\title{
Origins of chlorine in MSW and RDF: species and analytical methods
}

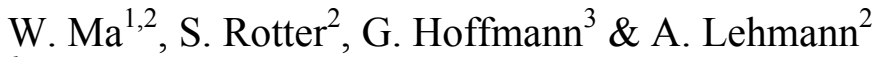 \\ ${ }^{1}$ Tianjin University, Faculty of Environmental Science and Engineering, \\ China \\ ${ }^{2}$ Berlin Institute of Technology, \\ Department of Environmental Engineering, Germany \\ ${ }^{3}$ Dresden University of Technology, Chair for Waste Management, \\ Germany
}

\begin{abstract}
The chlorine content of municipal solid waste (MSW) and refuse derived fuel (RDF) plays a dominant role in combustion processes. In order to prevent operational problems, such as high temperature corrosion, quality assured analytical methods for the determination of the chlorine concentration are necessary. This paper presents results of the chlorine content of the main components of untreated municipal solid waste. Various analytical methods have been compared with samples with a differing matrix and chlorine speciation. The comparison intends to not only estimate overall content of chlorine in mixed waste, but also to clarify chlorine species/origin in various components which have further influence on chlorine thermal behavior during combustion.

Keywords: chlorine, MSW, quality assured analytical methods, total chlorine content (TCC), elemental analyser (EA).
\end{abstract}

\section{Introduction}

One of the major issues continuously challenging environmental management and pollution control at present is the safe disposal of municipal solid wastes (MSW). Incineration seems to be one of the alternative strategies for waste management proposed to replace landfilling. One option for utilizing MSW as a fuel is to process it to refuse derived fuel (RDF) aiming at improving its fuel characteristics. However, both MSW and RDF contain a large quantity of 
chlorine, which frequently is causing high temperature corrosion in waste-toenergy (WTE) plants. To prevent operational problems, basic knowledge of the fuel property is necessary and detailed information on total chlorine content and chlorine species in main components of MSW is required.

Nevertheless, heterogeneous characteristic of MSW and RDF lead to the difficulty in determining chlorine concentration. Thus, several analytical methods were developed, such as calorimetric bomb (CB) and ion chromatography (IC) [1], improved quartz furnace methods with a differentiation of combustible and incombustible chlorine [2], Schoeniger flask method, elemental analyzer (EA) and X-Ray Fluorescence [3]. Since no general agreement was made, an appropriate method of determining chlorine in MSW and RDF should be further considered.

The objectives of this paper are

a) to determine the overall chlorine concentration in major waste components;

b) to specify the origin of chlorine in the major waste components;

c) to compare various analytical methods and identify an appropriate method to determine chlorine content.

\section{Materials and methods}

\subsection{Materials}

Since the thermal behaviour of chlorine in organic waste such as kitchen and garden waste during combustion has significant difference from organic bound chlorine in plastics, the following relevant components were selected in this investigation to differentiate between organic chlorine and inorganic chlorine:

- Household kitchen waste-Org1

- Household garden waste-Org2

- Packaging plastic bottles and containers-P11

- Packaging plastic films and bags-P12

- Non-packaging plastic products-P13

- Paper, cardboard-Paper

- Textile including clothes, carpets, old shoes and others-Textile

- Wood-Wood

All samples were sorted out of mixed residual waste from private households. That is why the sample still contains impurities from wet adhesions.

\subsection{Sample preparation}

Schirmer et al [4] introduced the sampling and sample preparation in detail. Figure 1 summarizes the preparation procedure.

\subsection{Analytical methods}

In this paper, two analytical methods have been developed for the differentiation:

Combustible and incombustible chlorine (or chlorine in gas and residues); 


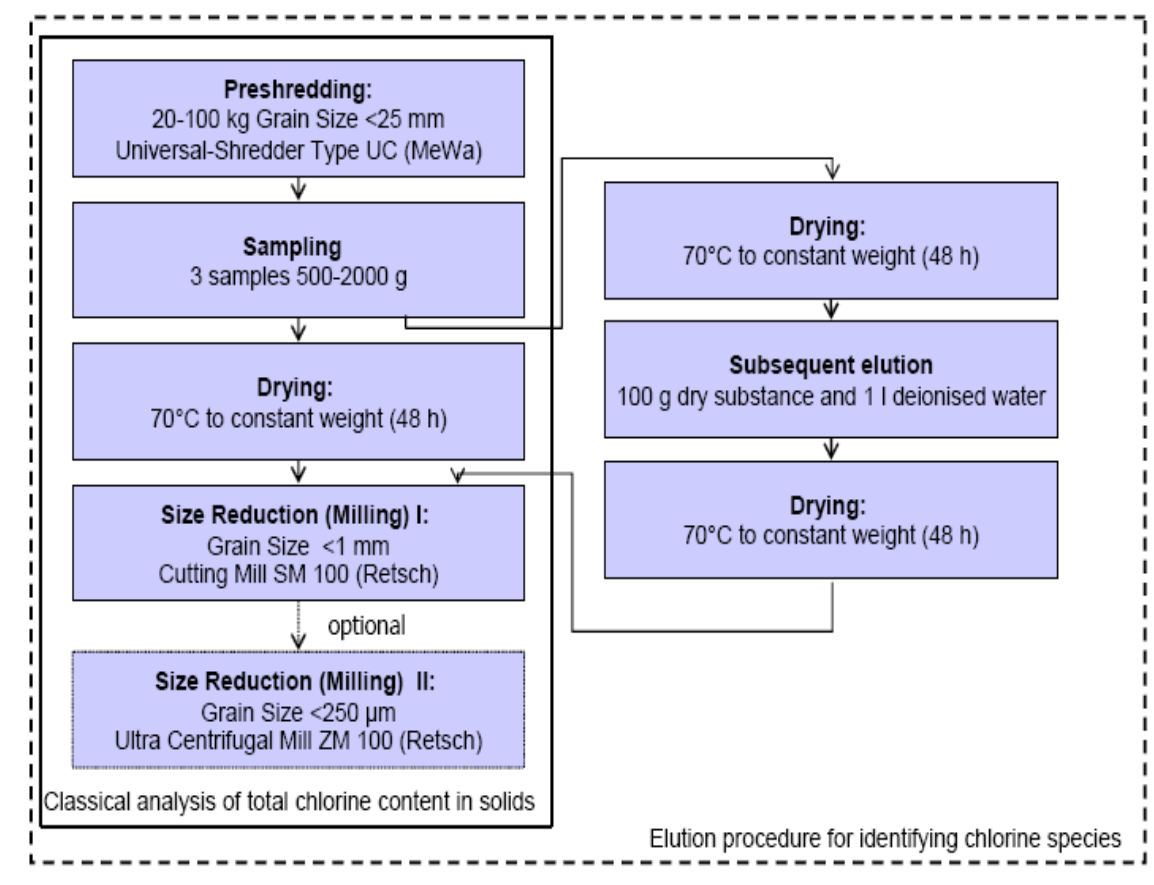

Figure 1: $\quad$ Sampling and sample preparation [4].

Organic and inorganic chlorine (or water-soluble chloride and water-insoluble chlorine) - elution test.

Those results are compared to the total chlorine content (TCC) measured by a calorimetric bomb (CB) digestion with a subsequent detection of chloride by ionic chromatography (IC) according to CEN/TS 15408:2005. The comparison intends to not only estimate overall content of chlorine, but also to clarify chlorine species/origin in various components which have further influence on chlorine thermal behavior during combustion.

\subsubsection{Elemental analyzer (EA) - Coulometry}

An automated instrumental analysis - the elemental analyzer (Analytik Jena multi ${ }^{\circledR}$ EA 2000) is introduced in this study.

The sample is burnt in a quartz tube in an oxygen rich atmosphere. The temperature can be chosen up to $1000^{\circ} \mathrm{C}$. During combustion inorganic chloride salts, such as $\mathrm{NaCl}$ and $\mathrm{KCl}$, are partly transferred into the gaseous phase. But a non-volatile part still remains in the ash. In difference organic bound chlorine is completely converted to $\mathrm{HCl}$, according to the following reaction:

$$
\mathrm{R}-\mathrm{Cl} \rightarrow \mathrm{HCl}+\mathrm{CO}_{2}+\mathrm{H}_{2} \mathrm{O}+\text { Oxides }
$$

The $\mathrm{HCl}$ is determined by a coulometric detector in the cell. After combustion, the incombustible chlorine as a form of ash on the quartz boat needs 
to be carefully rinsed with distilled water and diluted to $50 \mathrm{ml}$, finally for ion chromatography determination.

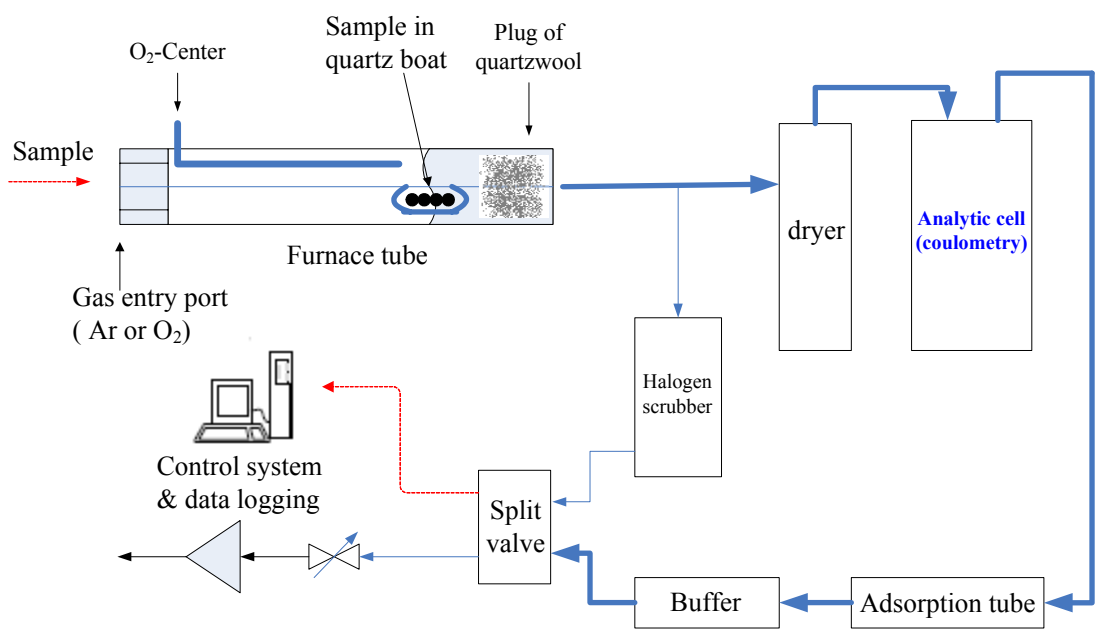

Figure 2: $\quad$ Flow diagram for operating with split gas.

\subsubsection{Elution procedure}

Schirmer et al [4] described the elution procedure. Since chloride salts in organic waste are well soluble, the chloride loading can be eluted with distilled water. The remaining insoluble water in the solid matter is assumed to be organic bound chlorine. The chloride concentration in all liquid elution samples is measured by ion chromatography after filtration at $20 \mu \mathrm{m}$. The total chlorine content in the dried solid matter after elution is measured by the Schoeniger Combustion.

\subsubsection{Calorimetric bomb (CB) and ion chromatography (IC)}

The combined calorimetric bomb (CB) and ion chromatography (IC) method for determination of chlorine (or applied to the analysis of different wastes and fuels) has been standardized by CEN/TS 15408: 2005. The principle of a calorimetric bomb is the complete destruction of the organic matter of waste samples. The high combustion temperature of $1000-1500^{\circ} \mathrm{C}$ and oxygen partial pressure ensure the transfer of organic halogen into the corresponding halogenides [5].

An oxygen bomb (IKA C 7000) with stainless steel reactor ( $210 \mathrm{ml}$ volume) is used, with $10 \mathrm{ml}$ of an absorbent solution $\left(2.52 \mathrm{~g} / 1 \mathrm{Na}_{2} \mathrm{CO}_{3}, 2.54 \mathrm{~g} / \mathrm{l} \mathrm{NaHCO}_{3}\right.$, $25 \mathrm{ml} 30 \% \mathrm{H}_{2} \mathrm{O}_{2}$ in 11 distilled water). After combustion, the gas and absorption are collected to test total chlorine, which is made up of two parts: Absorption in bomb and not absorbed chlorine in gas. After filtration the concentration of chlorine is determined by IC (Metrohm ${ }^{\mathbb{B}}$ IC 732). 


\section{Results and discussion}

\subsection{Chlorine concentration in major waste components - EA}

In the experimental procedure of EA, the sample combustion temperature is set to $850^{\circ} \mathrm{C}$.
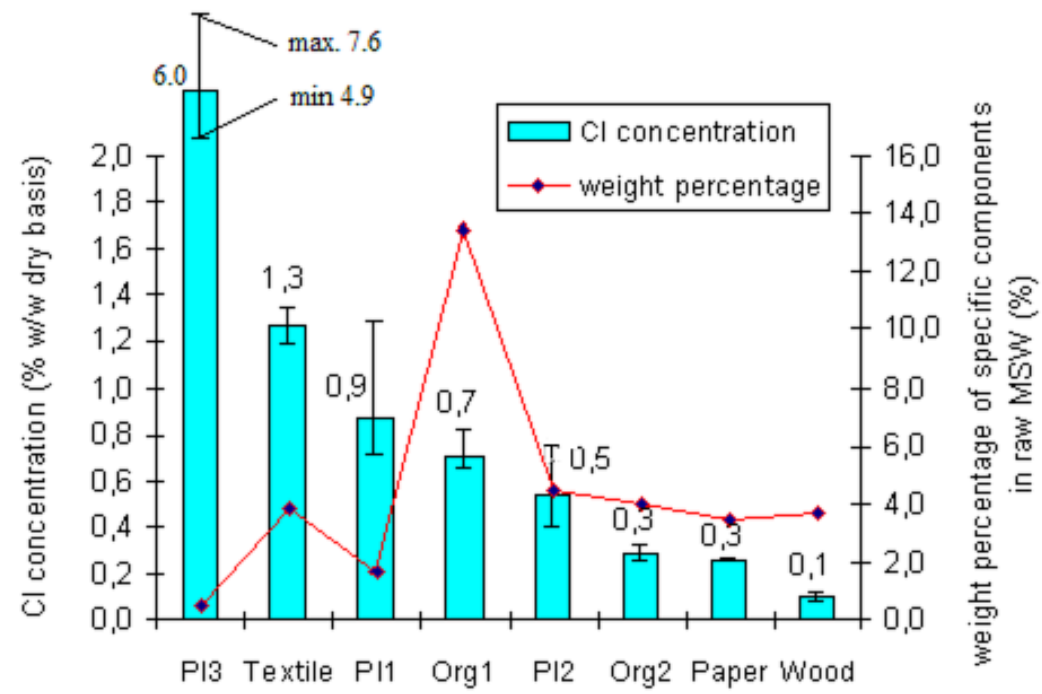

Figure 3: Chlorine concentration and weight percentage from MSW $\left(\mathrm{T}=850^{\circ} \mathrm{C}\right)-\mathrm{EA}$.

The chlorine concentration and weight percentage in major MSW components is shown in Fig 3. It is evident that there are significant differences among the chlorine concentration of the regarded waste components. They cover a range from $0.1 \%$ (w/w dry basis) in wood up to $6.0 \%$ (w/w dry basis) in nonpackaging plastics (P13). The non-packaging plastics in accordance with other researchers [6] have the highest chlorine concentration due to polyvinylchloride (PVC). This also supports the argument that chlorine in MSW could be reduced significantly if PVC is removed prior to incineration. The chlorine concentration of textiles with $1.3 \%$ (w/w dry basis) chlorine is rather high compared to other components, because old shoes also contain PVC. Furthermore, the plastic samples indicate a large range of chlorine concentration (difference by max. and min.), which could be explained by plastics heterogeneity. Kitchen waste contributes $13 \%(\mathrm{w} / \mathrm{w})$ as the largest part to total weight because of high water content.

\subsection{Identification of chlorine species - EA}

Knowledge about total chlorine content is not sufficient, since the thermal behavior of organic chlorine and inorganic chlorine is significantly different. A 
differentiation of chlorine species allows one to predict the behavior of chlorine in the combustion. It is illustrated in Figure 4 the chlorine differentiation of organic chlorine and inorganic chlorine by elution test and combustible chlorine and incombustible chlorine by EA lead to different results

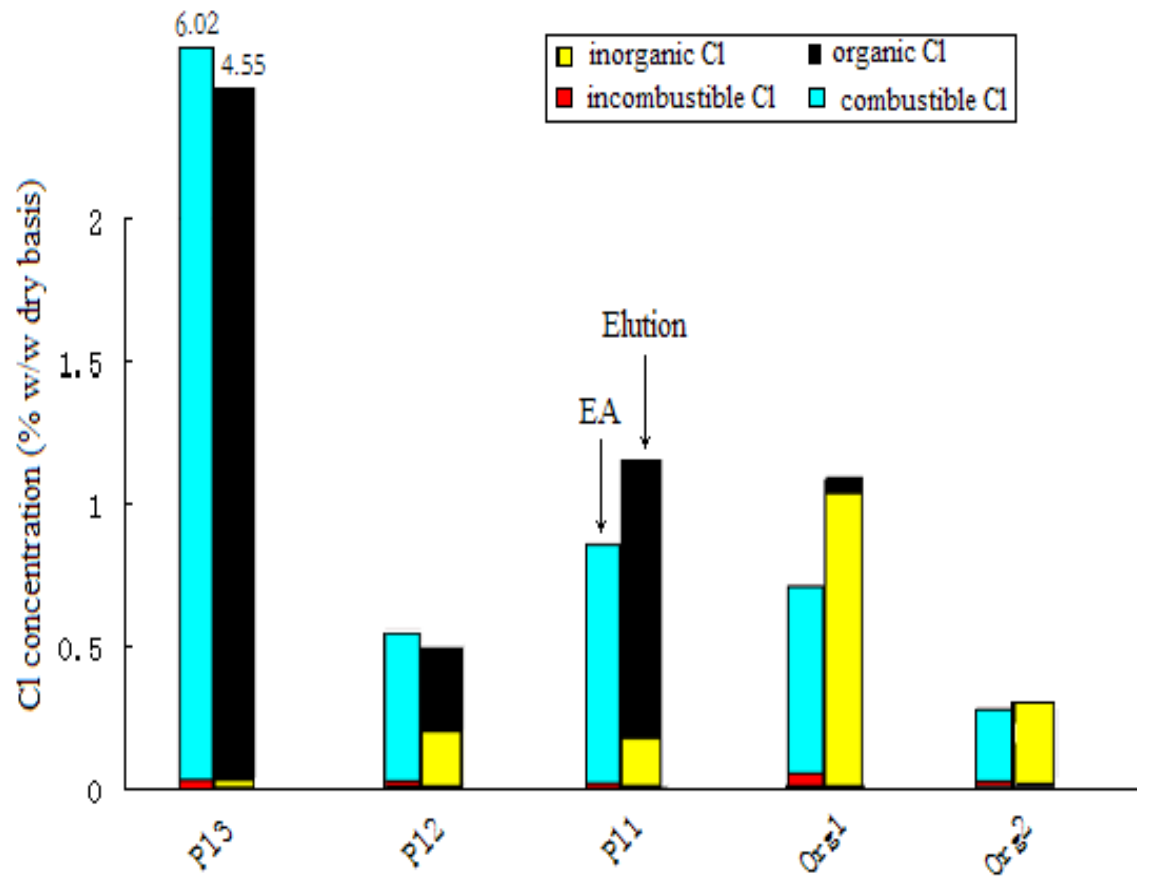

Figure 4: Chlorine specification by EA and elution test.

As expected kitchen and garden wastes contain mainly inorganic chlorine that is easily soluble by elution results. In plastics the content of inorganic chlorine is lower than organic chlorine.

However, the results of EA show deficits in the equal detection of combustible chlorine and incombustible chlorine. In other studies the detected combustible chlorine amounts $2.7 \mathrm{~g} \mathrm{Cl} / \mathrm{kg}$ versus incombustible $1.0 \mathrm{~g} \mathrm{Cl} / \mathrm{kg}$ [7]. This accords a ratio of 63:37, which is quite far away from the detected 95:5 in the present study. The incombustible chlorine increases, if the burning temperature decreases. An explanation for the low recovery of chlorine in incombustible chloride could be some insoluble compounds such as other chlorinated aromatic hydrocarbons or unknown compounds that are not able to be recovered with distilled water. Another reason could be a loss in the EA system because the detection is significantly lower than comparable methods. Therefore, a more detailed study is desirable to elucidate the incombustible chlorine content in future work. 


\subsection{Comparison of analytical procedures}

When these methods are compared, the CB\&IC method is observed to be slightly lower than the results with EA in components of pll and textile. This could be caused by incomplete combustion in the bomb or loosing chlorine when venting the bomb. In comparison with elution test, EA recovers $30 \%$ chlorine lower of org1. It can be assumed that the combustion temperature of around $850^{\circ} \mathrm{C}$ and the retention time in the furnace are insufficient to completely vaporize the alkali chlorides in organic waste.

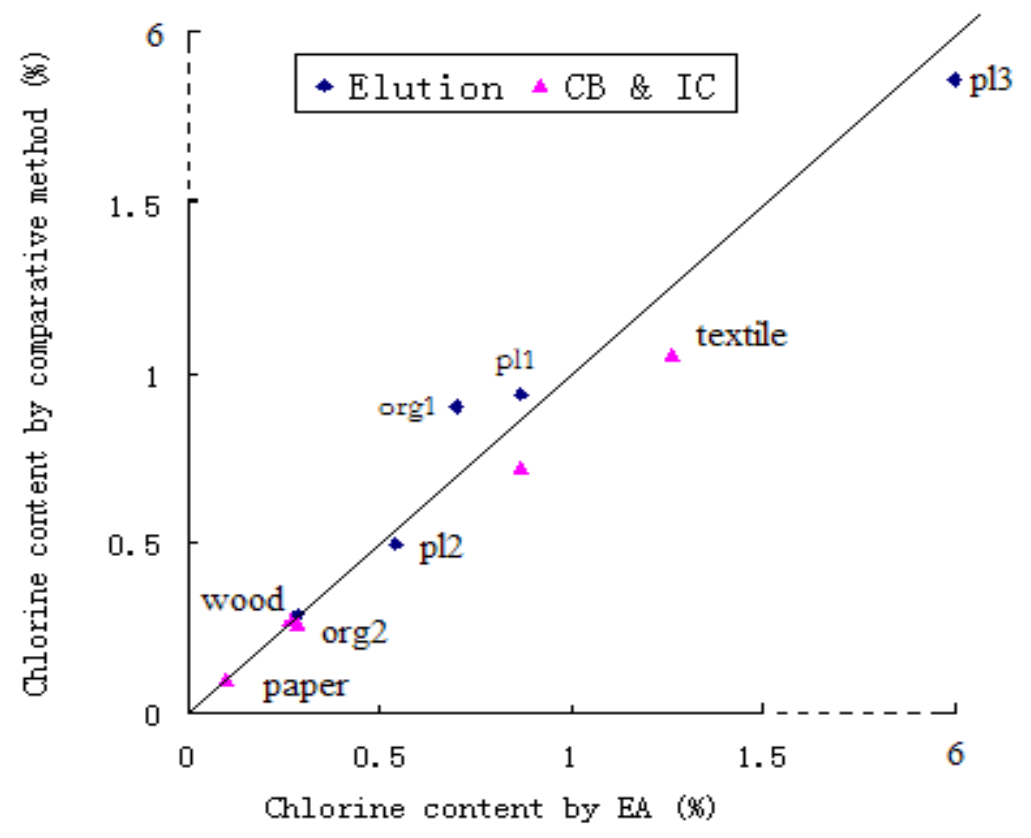

Figure 5: Chlorine content determined by EA in comparison with other methods.

As a result, elution test could recover more inorganic chloride salts; EA seems to be a more precise method to recover organic chlorine, although the detection of incombustible chlorine needs further development.

\section{Conclusion}

Based on the work thus far, following conclusions could be drawn:

1. The chlorine concentration in representative MSW samples covers a wide range from 0.1 to $6.0 \%$ (w/w dry basis). Non packaging plastics due to a widely use of PVC in past years contain highest concentration of chlorine; 
2. Regarding the chlorine bonding form, kitchen and garden wastes contain mostly inorganic chlorine whereas plastics contain more organic than inorganic chlorine. Meanwhile, the test shows weakness in equal detection of combustible chlorine and incombustible chlorine.

3. Compared to calorimetric bomb \& ion chromatography, elution test could recover more inorganic chloride salts; elemental analyzer seems to be a more precise method to recover organic chlorine, although the detection of incombustible chlorine needs further development.

\section{References}

[1] Cortes-Pena, M.A., Perez-Arribas L.V., Leon-Gonzalez M.E. \& Polo-Diez L.M., Determination of chlorine and bromine in automotive shredder residues by oxygen bomb and ion chromatography, Waste Management \& Research, 20, pp. 302-307, 2001.

[2] Watanabe N., Tanikawa N., Oikawa T., Inoue S., Fukuyama J. Improved quartz furnace method for chlorine and sulfur determination in municipal solid waste, Mater cycles waste management, 5, pp. 69-76, 2003.

[3] Schirmer, M., Bilitewski, B., Rotter, S. Source of chlorine in MSW \& RDFspecies, analytical methods and behavior in treatment processes, Proc. of $20^{\text {th }}$ Int. Conference On Solid Waste Technology and Management, Philadelphia, PA USA, 2005.

[4] Schirmer, M., Janz, A., Bilitewski, B., Rotter, Source of chlorine in MSW \& RDF- species, analytical methods and requirements on improved separation methods, Proc. Sardinia, Tenth Int. Waste Management and Landfill Symposium, S. Margherita di Pula, Cagliari, Italy, 2005.

[5] Rotter, S., Kost, T., Winkler, J., Bilitewski, B., Material flow analysis of RDF-production processes. Waste Management 24 (10), pp. 1005-1021, 2004.

[6] Schirmer, M., Ma, W., Hoffmann, G., Rotter, S., Origin and fate of chlorine in RDF production processes. Proc. Sardinia, Eleventh Int. Waste Management and Landfill Symposium, S. Margherita di Pula, Cagliari, Italy, 2007.

[7] Watanabe, N., Yamamoto, O., Sakai, M., Fukuyama, J. Combustible and incombustible speciation of $\mathrm{Cl}$ and $\mathrm{S}$ in various components of municipal solid waste, Waste management 24, pp 623-632, 2004. 